\title{
5-Fluorouracil in the Treatment of Keloids and Hypertrophic Scars: A Comprehensive Review of the Literature
}

\author{
Vidhi V. Shah · Adam S. Aldahan - Stephanie Mlacker · Mohammed Alsaidan • \\ Sahal Samarkandy $\cdot$ Keyvan Nouri
}

Received: March 22, 2016/Published online: April 22, 2016

(C) The Author(s) 2016. This article is published with open access at Springerlink.com

\begin{abstract}
Hypertrophic (HTSs) and keloid scars are common dermatological complaints produced by disruption of the normal wound-healing process. Despite a wide array of therapeutic options available to treat these lesions, HTSs and keloids continue to pose a significant challenge to clinicians in everyday practice. The chemotherapeutic drug 5-fluorouracil (5-FU) is a well-known treatment option

that 5-FU is a safe and practical alternative for the treatment of HTSs and keloids as it may substantially improve the appearance of proliferative scars and reduce the chance of recurrence. This therapeutic option is most effective in conjunction with adjuvant therapy such as corticosteroids. Additional randomized controlled clinical trials with large sample sizes should be conducted to corroborate the existing efficacy and safety data in patients with HTSs and keloids.
\end{abstract} reserved for recalcitrant HTSs and keloid lesions. We present clinicians with a comprehensive review of the published data concerning the use of 5-FU in the treatment of HTSs and keloids. The current evidence suggests

Enhanced content To view enhanced content for this article go to http://www.medengine.com/Redeem/ D7B4F06021217B16.

Electronic supplementary material The online version of this article (doi:10.1007/s13555-016-0118-5) contains supplementary material, which is available to authorized users.

V. V. Shah $(\bowtie) \cdot$ A. S. Aldahan · S. Mlacker .

M. Alsaidan · S. Samarkandy · K. Nouri

Department of Dermatology and Cutaneous

Surgery, University of Miami Miller School of

Medicine, 1475 NW 12th Ave. Suite 2175, Miami,

FL 33136, USA

e-mail: shahvidhiv@gmail.com

Keywords: 5-FU; Fluorouracil; Hypertrophic scars; Keloids; Scars

\section{INTRODUCTION}

Hypertrophic (HTSs) and keloid scars are commonly encountered complaints in dermatological practice [1]. These abnormal lesions are clinically challenging to treat and can be a source of significant distress to both patients and providers [2]. Lesions exhibit no gender preference, but principally emerge in younger individuals and ethnicities with darker complexions, such as African Americans, 
Asians, and Hispanics [1, 3]. An estimated $5-16 \%$ of African Americans and Hispanics experience keloid lesions [1]. Additional risk factors include a personal history of proliferative scars, a family history of HTSs or keloids, and inflammation in and around a wound site [4]. There is currently no explanation for the underlying pathogenesis of HTSs and keloids. These lesions may depict an aberrant wound-healing response to external physical trauma and represent an underlying complication of the extracellular matrix remodeling process $[3,5]$. Lesions can present anywhere on the skin surface where physical trauma has occurred; however the ear lobes, face, arms, shoulders, back, and chest are the most commonly afflicted anatomic locations. HTSs and keloids are differentiated clinically by the extent of tissue overgrowth with respect to the boundaries of the original wound [6]. HTSs are white to pink colored and persist along the margins of the original wound [7]. Contrastingly, keloid lesions are deep red to purple and have the capacity to proliferate well beyond the original borders of the wound $[3,5$, 8]. Table 1 compares non-hypertrophic and fibroproliferative scars.

Reasons to pursue treatment for HTSs and keloids include aesthetic considerations related to the psychological stress of cosmetic disfigurement or physical complaints including pain and pruritus [9]. Countless pharmacological agents have been investigated as monotherapy or in various combinations for scar therapy such as surgical excision, occlusive dressings, topical and intralesional corticosteroids, interferon, cryosurgery, radiation, pressure therapy, laser therapy, retinoic acid, and silicone gel sheeting [7]. Recently published studies investigate the value of laser therapy, including the flash-lamp pulsed dye, fractional carbon dioxide laser, copper bromide laser, and UVA1 laser [10-13]. Despite an array of therapeutic approaches, no single method provides complete benefit. For this reason, the medical care of HTSs and keloids remains clinically challenging, owing to variable efficacies, side effect profiles, and high instances of recurrence [3].

Chemotherapeutic drugs are also utilized as a treatment option for recalcitrant and recurrent HTSs and keloids [14]. Five-fluorouracil (5-FU) is a pyrimidine analog that inhibits the synthesis of deoxyribonucleic acids by irreversibly inhibiting thymidine synthase, which is responsible for converting uridine to thymidine. Without the structural elements of biosynthesis, rapidly proliferating cells such as fibroblasts are halted and scar degradation is

Table 1 Comparison of non-hypertrophic scars and fibroproliferative scars [39]

\begin{tabular}{lll}
\hline Scar type & Scar type subclass & Clinical characteristics \\
\hline Non-hypertrophic & Atrophic & Depressed \\
Textural & Mature light color, flat \\
& Immature red, pruritic, painful, slightly elevated \\
Fibroproliferative & Linear red, raised, pruritic \\
& Kelortrophic & Widespread red, raised, pruritic, extensive \\
& Minor focally raised, pruritic \\
& Major $>0.5 \mathrm{~cm}$, painful, pruritic \\
\hline
\end{tabular}


promoted [4]. Additionally, 5-FU is believed to hinder type I collagen gene expression and the effects of tumor growth-beta 1. Studies have discovered a dose-related association between 5-FU and reduction in keloid fibroblast proliferation and the fibroblast-populated collagen lattice. In 1999, Fitzpatrick first introduced 5-FU for the treatment of HTSs and keloids [15]. Subsequent investigators have endorsed 5-FU as a viable treatment option and have explored 5-FU combined with adjuvant modalities to enhance its efficacy [16]. In this comprehensive review, we provide clinicians with the currently published studies involving 5-FU for the treatment of HTSs and keloids.

\section{METHODS}

We sought to obtain all available published data that studied the treatment of HTSs and keloids with 5-FU as an individual agent or 5-FU plus adjuvant treatment. For the purposes of this review, the agents considered adjuvant treatments included corticosteroids, lasers, botulinum toxin, or silicone sheets. Importantly, excision was not considered adjuvant treatment, and the combination of excision and 5-FU was considered monotherapy. A broad literature search in PubMed, Medline, EMBASE, Cochrane Central Register of Controlled Trials (CENTRAL), and Google Scholar was performed on November 2015. To search for the conditions of interest, we used the terms 5-FU, fluorouracil, hypertrophic scar, keloid, and scar in various combinations. The search strategy for PubMed is shown in Appendix 1 (Electronic Supplementary Material). Only citations in English and involving human subjects were included. Studies published online and in print and from all years were considered. Titles and abstracts were screened for relevance to our topic. Two authors independently reviewed the relevant full text articles and each extracted datum, which was consolidated into a standardized table. A third author resolved any differences. Reference lists of the included trials were screened for additional eligible publications. The search was rerun in December, January, and February for recently published articles. This article is based on previously conducted studies and does not involve any new studies of human or animal subjects performed by any of the authors.

\section{RESULTS}

The preliminary literature search produced 147 citations. After filtering the search according to inclusion criteria, 69 titles and abstracts were screened for relevance. After screening, a total of 21 articles were included in this review. The selected articles include: ten randomized controlled trials, four prospective single-arm trials, four case series, two case report(s), and an expert opinion. Table 2 presents the treatment regimen and clinical outcomes of studies involving intralesional 5-FU monotherapy and intralesional 5-FU with adjuvant corticosteroid therapy.

\section{Intralesional 5-FU Monotherapy}

Gupta and Kalra treated 24 consecutive patients with $50-150 \mathrm{mg}$ intralesional injections of $50 \mathrm{mg} / \mathrm{ml}$ of 5 -FU using 1-week injection intervals for a total of 16 injections. Clinical evaluation by a single observer was done at treatment, cessation of treatment, and the follow-up period. Excellent flattening was seen in $33.3 \%$ of patients, and more than $70 \%$ 


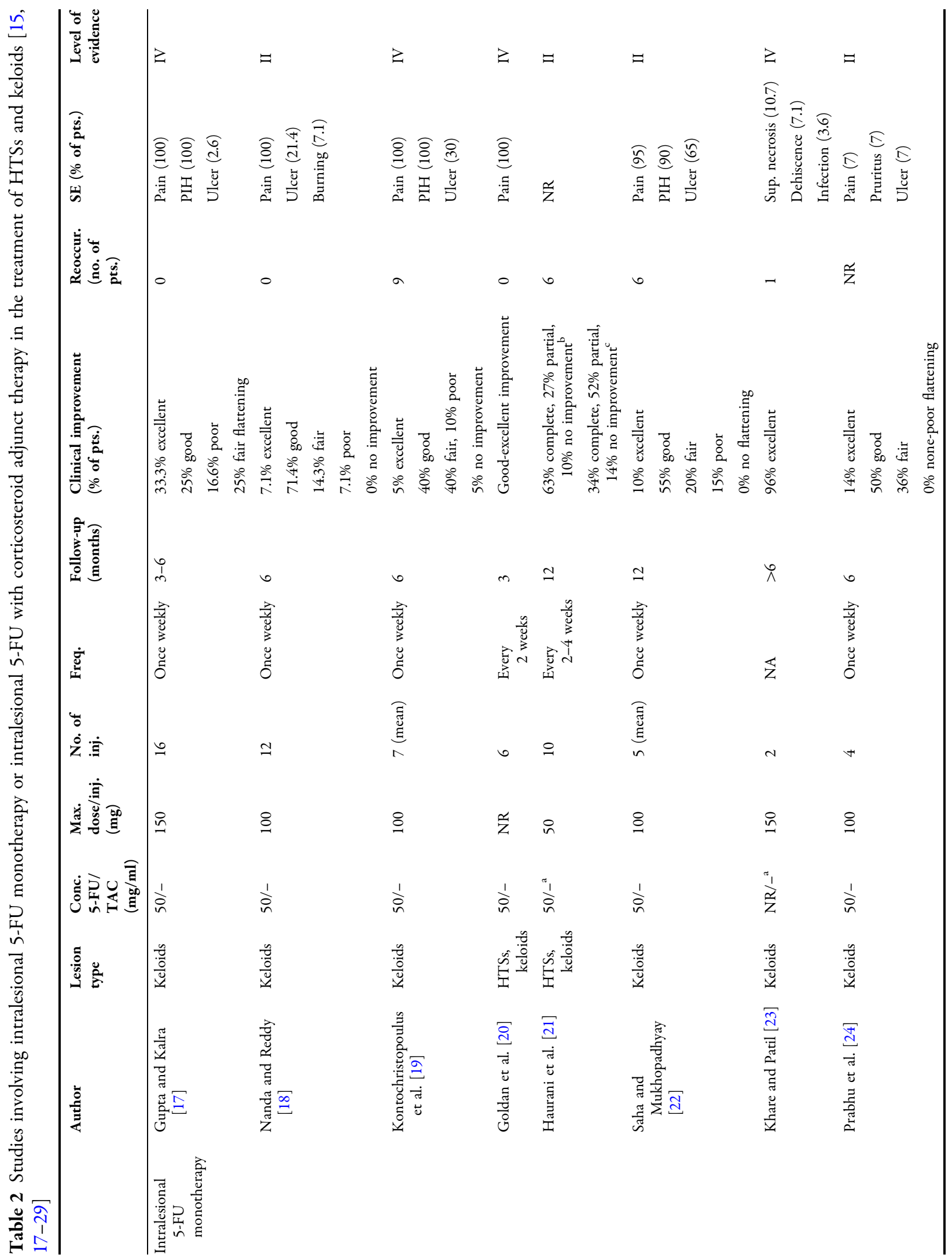




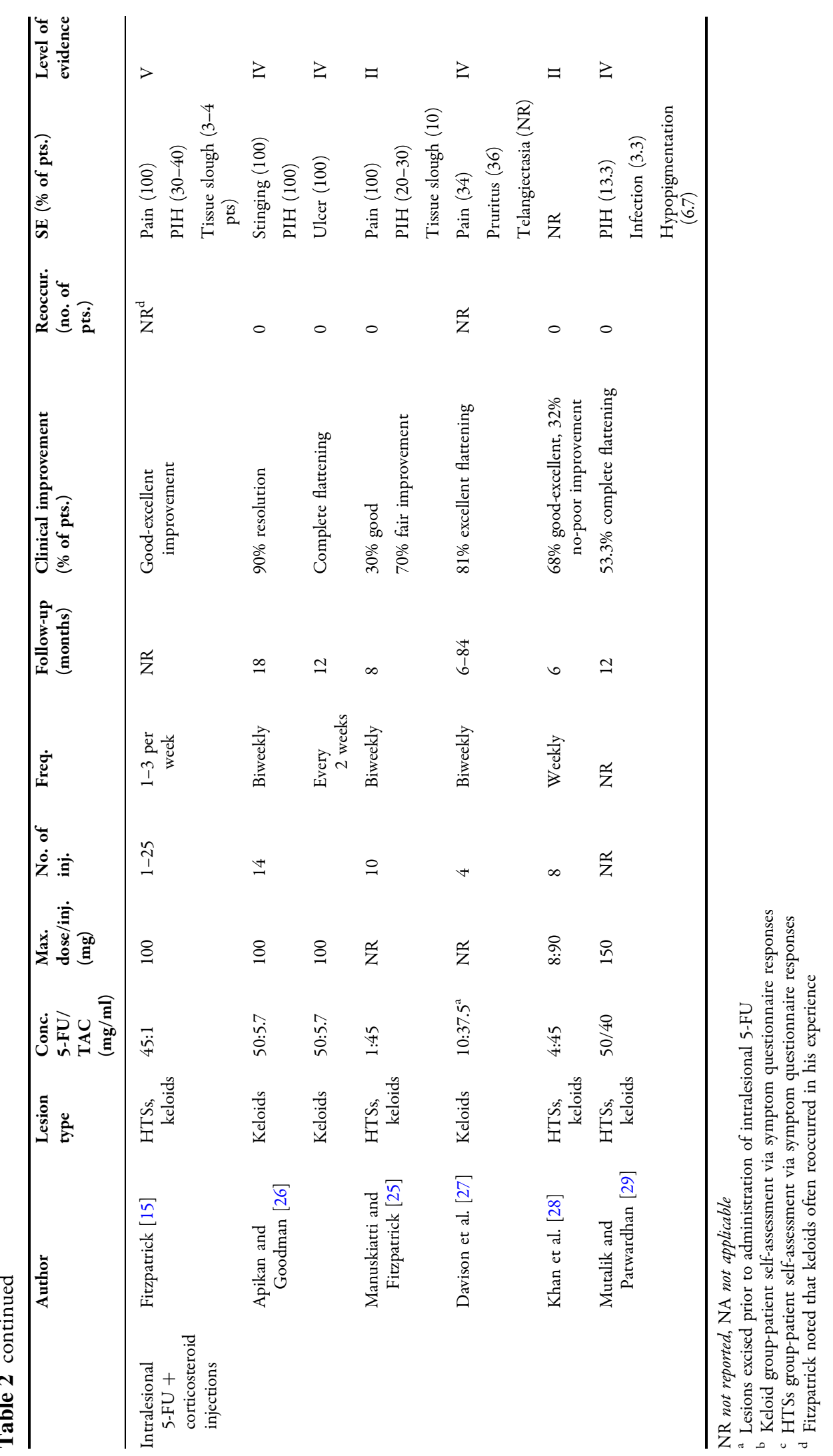


patients reported decreased itching, pain, and discharge. Side effects of treatment included pain and hyperpigmentation in all 24 patients as well as ulceration in 1 patient. There were no reoccurrences in patients who were followed up at 3-6 months [17].

In a similar study, Nanda and Reddy studied the effects of 5-FU in 28 patients with keloids on the chest, shoulder, upper arms, back, and additional locations. Eight patients had previously failed to respond to triamcinolone acetonide (TAC) $40 \mathrm{mg} / \mathrm{cc}$ injections every 3 weeks. Weekly intralesional injections of $0.5-2 \mathrm{ml}$ of $50 \mathrm{mg} / \mathrm{ml} 5$-FU per session were administered for no more than 12 weeks. There was good improvement in $71.4 \%$ patients and excellent improvement in $7.1 \%$ patients. Follow-up at 24 weeks revealed no recurrences. Adverse effects included pain in $100 \%$, ulceration in $21.4 \%$, and burning in $7.1 \%$ of patients [18].

Kontochristopoulus et al. also investigated the effects of intralesional 5-FU in 20 patients with keloid lesions on various locations including the chest, back, extremities, and earlobes. Eleven patients had previously failed treatment with steroid injections, silicone gels, surgical excision, and cryotherapy. Weekly intralesional injections of $0.2-0.4 \mathrm{ml} / \mathrm{cm}^{2}$ of $50 \mathrm{mg} / \mathrm{ml} 5$-FU were administered over an average of seven sessions. Forty percent of patients had good improvement, and 5\% had excellent improvement. At 52-week follow-up, $47 \%$ demonstrated reoccurrence. All patients experienced pain and transient hyperpigmentation, and six patients had superficial ulceration [19].

Goldan et al. utilized 5-FU injections to treat a 67-year-old female with facial HTSs and keloids following dermabrasian facial resurfacing. The patient had achieved only mild improvement with previous treatments including acyclovir, prednisone, fucidic acid, fexofenadine, betamethasone, and local silicone sheets with intralesional methylprednisolone acetate. Serial intralesional injections of $50 \mathrm{mg} / \mathrm{ml} 5$-FU in six sessions over 3 months produced significant improvement of post-dermabrasian HTSs and keloids, with noticeably smaller, softer scars and less erythema. Local anesthesia with $1 \%$ lidocaine was administered prior to injections, and silicone sheets were applied following treatment. The patient experienced few side effects throughout the treatment and complete resolution of pain and pruritus [20].

Haurani et al. evaluated the effects of excision followed by intralesional 5-FU in 32 patients with keloid lesions and 21 patients with HTSs. All had previously failed corticosteroid therapy, and many failed other conventional treatments. Scars were administered $50 \mathrm{mg} / \mathrm{ml} \quad 5$-FU intralesional injections every 2-4 weeks with a total dose of $500 \mathrm{mg}$. Additionally, keloids were excised 2 weeks prior to the start of intralesional series. Patients were assessed upon scar symptom questionnaire and scar volume. Fair or good improvement was noted in $27 \%$ of patients, and $63 \%$ experienced excellent improvement. Nineteen percent of patients experienced reoccurrence of lesions at 1-year follow-up [21].

In a study of 44 patients with keloid lesions, Saha and Mukhopadhyay compared intralesional 5-FU to $40 \mathrm{mg} / \mathrm{ml}$ TAC injections (RCT control). Weekly $50-\mathrm{mg} / \mathrm{ml}$ intralesional 5-FU was administered over an average of five sessions. Seventeen of 20 patients $(85 \%)$ in the 5-FU group achieved fair to excellent flattening of lesions. Thirty-five percent of patients experienced reoccurrence of lesions at 6 months post-treatment. Both treatment regimens were equally effective in reducing 
keloid volume, but the side effects were noticeably worse in the 5-FU group, with $95 \%$ experiencing extreme pain and $65 \%$ experiencing superficial ulcerations [22].

In a similar manner, Khare and Patil compared intralesional 5-FU plus excision in 28 patients to intralesional TAC (control) in 24 patients with ear keloids. Patients in the treatment group received $50-150 \mathrm{mg} / \mathrm{ml} 5-\mathrm{FU}$ intralesional injections following excision. Ninety-six percent of patients in the treatment group demonstrated reduced keloid size at the end of 1 year. Fewer instances of recurrences occurred in the treatment group (4\%) as compared to the control group (22\%). Side effects of therapy included superficial necrosis in three patients, partial wound dehiscence in two patients, and local infection in one patient [23].

Prabhu et al. also compared the efficacy of weekly intralesional injections of $50 \mathrm{mg} / \mathrm{ml}$ 5 -FU versus $40 \mathrm{mg} / \mathrm{ml}$ TAC (control) in 30 patients with keloids for 4 weeks. Interestingly, good to excellent flattening of keloid size was seen in $64 \%$ of patients in patients receiving 5 -FU versus $87 \%$ in patients receiving TAC monotherapy, and the difference was statistically significant. More complications were encountered in the 5-FU group and included ulceration in one patient, pruritus in one patient, and pain in one patient, but this distinction was not statistically significant [24].

\section{Intralesional 5-FU/TAC Combination}

In a series of observations involving more than 1000 patients over 9 years, Fitzpatrick recorded the use of 5-FU with and without different adjuvant therapies for the treatment of various scar types including keloids. All patients received intralesional injections of $50 \mathrm{mg} / \mathrm{ml}$ 5-FU without ever exceeding $100 \mathrm{mg}$ per treatment. Initially, patients received 5-FU monotherapy once monthly, which was found to be ineffective. With added time and experience, Fitzpatrick reported reduced pain and overall better outcomes with once-weekly injections (on average) of a mixture of $45 \mathrm{mg}$ / $\mathrm{ml} 5$-FU in combination with $1 \mathrm{mg} / \mathrm{ml}$ of TAC [15].

Manuskiatti and Fitzpatrick conducted a study involving ten patients with previously untreated median sternotomy HTSs and keloids. In a single study, several management options were compared by separating lesions into five segments: laser radiation with 585-nm pulsed-dye laser (PDL), TAC, intralesional 5-FU, and intralesional TAC in combination with 5-FU (5-FU/TAC), and untreated control. In 5-FU sections, intralesional injections of $50 \mathrm{mg} / \mathrm{ml} 5$-FU were administered every 2 weeks for the first eight treatments and every 4 weeks for the last two treatments. All treated segments demonstrated significant improvement; however, no method demonstrated superiority over the others. Intralesional 5-FU and 5-FU/TAC demonstrated significant lesion flattening as compared with baseline by week 8 . Scar erythema was reduced at week 16 and week 24 with 5-FU and 5-FU/ TAC, respectively, compared to baseline. Scar pliability was increased at week 8 with 5 -FU/ TAC and by week 16 with 5-FU monotherapy. Subjects receiving 5-FU revealed $70 \%$ with fair improvement and 30\% with good improvement on self-assessments at 32 weeks. All patients who received 5-FU with or without adjuvant treatment noted pain and burning. One patient on 5-FU/TAC developed superficial ulceration [25].

Apikan and Goodman also investigated 5-FU in combination with betamethasone acetate (BA) and betamethasone sodium phosphate (BSP) in two patients with keloid scars. A 
mixture of $1.6 \mathrm{ml}$ of $50 \mathrm{mg} / \mathrm{ml} \mathrm{5-FU} \mathrm{with} 0.4 \mathrm{ml}$ of $3 \mathrm{mg} / \mathrm{ml}$ of BA and $3.9 \mathrm{mg} / \mathrm{ml}$ of BSP was injected every 2 weeks for 1 year. The study demonstrated a reduction in keloid size and minimal side effects with no recurrences at 1-year follow-up. Side effects included hyperpigmentation in both patients [26].

Davidson et al. conducted a retrospective review of 94 patients with 102 keloids. Keloids were separated into three treatment groups including: 5-FU/TAC without excision (52 subjects), 5-FU/TAC with excision (24 subjects), and TAC treatment with excision (26 subjects). A $3: 1$ concentration of $37.5 \mathrm{mg} / \mathrm{ml}$ of 5 -FU and $10 \mathrm{mg} / \mathrm{ml}$ of TAC was mixed, and $0.1 \mathrm{ml}$ of solution per centimeter of lesion was injected. Excisional patients were given injections 2, 4, and 6 weeks after surgery, and non-excisional patients were administered injections every 4 weeks. A statistically significant reduction in keloid size was seen with 5FU/TAC regimens (92\%) as compared to TAC alone (73\%). Patients with keloids treated with 5-FU experienced pain and pruritus [27].

Khan et al. enrolled 150 patients to receive either intralesional $0.25 \mathrm{ml}$ of $40 \mathrm{mg} / \mathrm{ml}$ TAC diluted with $0.75 \mathrm{ml}$ normal saline or $0.9 \mathrm{ml}$ of $50 \mathrm{mg} / \mathrm{ml}$ of 5 -FU mixed with $0.1 \mathrm{ml}$ of $40 \mathrm{mg}$ / $\mathrm{ml}$ TAC. There was significant improvement with 5-FU/TAC compared to TAC monotherapy, with 63 5-FU/TAC patients (84\%) having good to excellent results compared to 51 TAC patients (68\%). There were no instances of scar recurrence at 6-month follow-up. Eighteen patients (24\%) who were administered TAC alone and six patients (8\%) who were given 5-FU/TAC experienced complications [28].

Mutalik and Patwardhan studied 30 patients with HTSs and keloids and administrated intralesional injections of $50 \mathrm{mg} / \mathrm{ml} \mathrm{5-FU.} \mathrm{TAC}$ $40 \mathrm{mg} / \mathrm{ml}$ was added in a $1: 1$ ratio for lesions with inflammation or firm induration. Patients were instructed to use sodium fusidate or mupirocin for 5 days following treatment and follow-up in 4 weeks; $67 \%$ of patients showed complete flattening of keloids with a mean of four injections. A quarter of these patients who improved with therapy developed reoccurrence of lesions at 1-year follow-up. Side effects included transient hyperpigmentation with 5-FU. Infection and hypopigmentation were seen in a few patients who received concomitant steroids [29].

\section{Intralesional 5-FU/TAC and Lasers}

Fitzpatrick also recounted successful treatment of scars with pronounced erythema using pretreatment with PDL therapy. In a 45-year-old female with HTSs and keloids following plastic surgery to the face, Fitzpatrick administered intralesional injections of $45 \mathrm{mg} / \mathrm{ml} 5-\mathrm{FU}$ and $1 \mathrm{mg} / \mathrm{ml}$ of TAC over 20 treatment sessions. Follow-up use of PDL $\left(6.25 \mathrm{~J} / \mathrm{cm}^{2}\right)$ demonstrated complete resolution of HTSs and keloids [15].

Alsilian et al. used lasers in combination with intralesional 5-FU/TAC for the treatment of keloids and HTSs. Sixty-nine patients were divided into three groups receiving different therapies: TAC $10 \mathrm{mg} / \mathrm{ml}$ injected at weekly intervals for 8 weeks, TAC +5 -FU $0.1 \mathrm{ml}$ of $40 \mathrm{mg} / \mathrm{ml}$ TAC added to $0.9 \mathrm{ml}$ of 5 -FU $50 \mathrm{mg} /$ $\mathrm{ml}$ injected weekly for 8 weeks, and 5-FU/TAC serial injections for 8 weeks, combined with 585 PDL $5-7 \mathrm{~J} / \mathrm{cm}^{2}$ at the $1 \mathrm{st}, 4 \mathrm{th}$, and 8 th weeks. Statistically significant improvement was found in patients receiving 5-FU/TAC and 5-FU/ TAC + PDL in contrast to TAC monotherapy. Average flattening of the lesion was $50 \%$ in the TAC group, $77 \%$ in the 5 -FU/TAC group, and $79 \%$ in the 5-FU/TAC + PDL groups. Patients in all three groups complained of pain associated with injections. Steroid atrophy and 
telangiectasia was seen with TAC monotherapy [30].

Darougheh et al. randomized 40 HTSs and keloid patients to receive either TAC alone or 5-FU/TAC. Weekly intralesional injections of $10 \mathrm{mg}$ TAC or a mixture of $4 \mathrm{mg}$ TAC and $45 \mathrm{mg}$ 5-FU were given for a total of eight treatments. There were statistically significant reductions in length, width, height, erythema, induration, and pruritus in both groups, with greater improvement in the 5-FU/TAC group. Greater than $50 \%$ improvement was reported in $20 \%$ of the TAC group versus $55 \%$ in the 5 -FU/TAC group. Trained observers also reported greater improvement in the 5-FU/TAC group; however, this difference was not statistically significant. Adverse events included pain, atrophy, and telangiectasia in those receiving steroids. Interestingly, the 5-FU/TAC group demonstrated no adverse effects besides injection pain [31].

Katz et al. described intralesional 5-FU/TAC in combination laser therapy in a 75-year-old female who developed perioral, hypertrophic scarring following a phenol peel for perioral rhytides. She had previously received intralesional 5-FU/TAC therapies with no improvement. Katz et al. attempted 595-nm PDL (7-9 J/ $\mathrm{cm}^{2}, 7-10-\mathrm{mm}$ spot size, 3-10-ms pulse width, with 21-55 pulses per treatment) followed by the $1450-\mathrm{nm}$ diode laser $\left(12-14 \mathrm{~J} / \mathrm{cm}^{2}\right.$, 6-mm spot size, 6-16 pulses per treatment). After each laser session, the patient was administered $10 \mathrm{mg} / \mathrm{ml}$ intralesional $\mathrm{TAC}$ and $50 \mathrm{mg} / \mathrm{ml} 5-\mathrm{FU}$. She experienced greater than $95 \%$ of aesthetic and functional improvement and no recurrence following ten treatment sessions. Side effects included temporary bruising [32].

\section{Additional Techniques}

Hatamipour et al. studied the effects of intralesional 5-FU with topical silicone in the prevention of keloids. Fifty patients with keloids of different sizes and varying durations were used to compare treatment with and without 5-FU. Any prior therapy was discontinued before enrollment. In the treatment group, keloids were excised, covered with topical silicone sheets, and administered a series of $50 \mathrm{mg} / \mathrm{ml} 5$-FU intralesional injections at postsurgical days $7,14,28$, and during the 2nd and 3rd months, with doses varying between 0.6 to $1 \mathrm{ml}$. The second group and controls received no 5-FU intralesional treatment; $75 \%$ of patients showed complete improvement versus $43 \%$ in the control group. Side effects included ulceration, burning, and pain at the injection site [33].

Uppal et al. studied 11 Afro-Caribbean patients with keloid scars on the earlobes, chest, or shoulders. Ten patients had previously received intralesional steroid treatment. Patients with bilateral earlobe keloids were randomized into control or treatment groups according to coin toss, and linear scars were split in half. Following excision, treatment lesions were given $50 \mathrm{mg} /$ $\mathrm{ml} 5$-FU intralesional injections in phosphate-buffered saline by a soaked sponge pledget for $5 \mathrm{~min}$. Control lesions were exposed to phosphate-buffered saline alone. Greater clinical improvement by lower keloid scar scores was appreciated in treated lesions than controls by blinded observers [34].

Sadeghinia and Sadeghinia developed a novel approach to administer 5-FU named "5-FU tattooing." The procedure of 5-FU tattooing includes anesthesia of lesions followed by dripping $1 \mathrm{ml}$ of $50 \mathrm{mg} / \mathrm{ml}$ of 5 -FU solution onto each centimeter area of the lesion. Forty punctures are made in the skin using a 27-gauge needle, and $1 \mathrm{ml}$ of 5 -FU solution was again dripped on the surface and covered in order to optimize absorption of 5-FU. The study involved 
40 patients randomized into an intralesional TAC group or 5-FU tattooing group. Patients who received any other treatment type in the past 6 months were excluded from the study. Patients received therapy every 4 weeks for a total of 12 weeks. At the end of the study, both groups demonstrated a reduction in size, erythema, induration, and pruritus. More than double the number of patients receiving 5-FU achieved good to excellent patient satisfaction scores as compared to those in the TAC group (85\% versus 40\%, respectively). Greater overall improvement was also appreciated by observer assessment in the 5-FU group. Ninety-five percent of patients in the 5-FU group achieved good to excellent results, whereas only $50 \%$ in the TAC group achieved a good to excellent response [35].

Wilson et al. utilized botulinum toxin to enhance the inhibitory effect on fibroblasts. Following surgical excision, 80 patients with keloids were injected with intralesional $50 \mathrm{mg}$ / $\mathrm{ml} 5$-FU with $50 \mathrm{IU} / \mathrm{ml}$ botulinum toxin, using a total dose of less than $140 \mathrm{U}$. All patients were treatment failures with various other methods. The mean follow-up period was 19.6 months over which only $3.75 \%$ experienced recurrence. More than $80 \%$ of patients reported significant improvement and $12.5 \%$ conveyed at least slight improvement. Complications included pruritus, pain, and residual post-inflammatory hyperpigmentation. One patient experienced partial wound dehiscence during the postoperative period. Eleven patients (13.75\%) experienced late widening of the scar, which resulted in corrective surgery at a later date in half [36].

\section{DISCUSSION}

Fibroblasts are imperative constituents of the normal wound-healing processes, of which there is three distinct stages including inflammation, proliferation, and maturation [4]. First, leukocytes and macrophages clean the wound of cellular debris and bacteria to prevent infection. Next, fibroblasts produce collagen, which gives tissue its tensile strength and structure. The wound site fills with granulation tissue, and the margins contract with the mobility of myofibroblasts allowing for epithelization. In the final phase of wound healing, collagen fibers remodel to improve the overall tensile strength [15]. Disruption of this normal-healing process results in the formation of HTSs and keloids [15].

A number of new strategies have been introduced for the treatment of HTSs and keloids in the past decade or so, including chemotherapeutic drugs. Observations from in vitro studies provide scientific evidence of 5-FU's ability to effectively suppress fibroblast proliferation and inflammation, thus reducing postoperative scar formation [37]. Other studies have also found that fibroblast suppression is dependent upon the duration and dosage of the drug. Several clinical studies have also investigated the effects of intralesional 5-FU on HTSs and keloids alone or in combination with other modalities. Thus, 5-FU offers an alternative management option for patients with HTSs or keloids experiencing unwanted effects or those who have previously failed other treatment options.

\section{Efficacy}

Use of intralesional 5-FU monotherapy achieves good to excellent scar improvement in $45-78 \%$ of patients. This effectiveness is further augmented with the addition of TAC, where $96 \%$ of patients achieve good to excellent results $[2,5]$. Seeing that, the combination of 5-FU and TAC seem to be more effective than either 5-FU or TAC administered alone [5]. 
Granted, a multitude of factors seem to contribute to the overall efficacy of 5-FU on HTSs and keloids including, but not limited to, drug dosage, intralesional regimen, scar size, and scar duration. Studies investigating the effects of 5-FU monotherapy used consistent drug dosages of $50 \mathrm{mg} / \mathrm{ml}$. When combined with TAC, the steroid combinations remained very low (TAC: 5 -FU of 1:45 or $4: 45 \mathrm{mg} / \mathrm{ml}$ ) [2]. Davison et al. tested greater dosages (TAC: 5 -FU $10: 37.5 \mathrm{mg} / \mathrm{ml}$ ) and appreciated increased instances of side effects, although this was not statistically significant. Thus, low doses of corticosteroids are recommended and its addition primarily functions to reduce the incidence of unwanted side effects. Also, lesions are more challenging to treat with added time, and this is true for 5 -FU as well as the majority of other existing scar therapies as well [6]. Such was the experience of Gupta and Kalra, who found a correlation between therapeutic response and keloid age, with keloids of less than or equal to 5-year duration achieving greater flattening than older keloids [17].

The effects of 585-nm PDL therapy on scars is well known in the literature [38]. Lasers target the scar microvasculature by selective photothermolysis, although the exact mechanisms by which it improves proliferative scars are unknown [7]. Very few studies have explored the effects of adjuvant laser radiation in the context of 5-FU and scar treatments, but those that have have successfully demonstrated positive results $[15,25,31,32]$. Fitzpatrick was the first to report his experience with 5-FU and PDL therapy and noted the benefits of less scar erythema [15]; of note, a follow-up study exhibited no superiority in efficacy with the addition of laser therapy [25]. In the same manner, Katz et al. were the first to report successful results of adjuvant therapy with the 1450-diode laser and also reported successful results [32]. The therapeutic benefits of laser therapy with 5-FU on scars likely improve scar texture and erythema [25], but it is difficult to comment on the exact efficacy of the combination of laser therapy with 5-FU because of the minimal evidence available. Additional studies are needed to clarify its efficacy with 5-FU, as there is insufficient evidence of this method.

\section{Safety and Recurrence}

5-FU drug toxicity is usually seen with intravenous dosing and primarily involves adverse hematologic effects such as anemia, thrombocytopenia, and leukopenia [34]. Patients with active or chronic infections, immune depression, and pregnant or lactating women should avoid 5-FU [39]. No systemic side effects following injection were observed in any of the studies discussed in this review. Several studies reported no side effects, and those that did reported adverse effects of erythema, ulceration, and dyspigmentation and significant pain at the injection site. These were generally transient or easily manageable. More serious side effects included dehiscence, widened scars, and tissue necrosis.

Corticosteroids are highly advantageous because of their multi-faceted inhibitory effects including the suppression of fibroblast and keratinocyte proliferation, reduction in inflammation, and vasoconstriction of blood vessels [15]. The disadvantages of potent corticosteroid use are its unpleasant side effects including telangiectasia, atrophy, rebound effects, ineffectiveness, and the pain of multiple injections [15]. With respect to corticosteroids, the literature is consistent and suggests that the 5-FU/TAC combination regimen is most effective on keloid scars and 
decreases 5-FU induced erythema and inflammation. Furthermore, the combination of 5-FU with corticosteroids decreases the incidence of such side effects that can be affiliated with steroid monotherapy.

Treatment intervals between injections may correlate with instances of side effects. Fitzpatrick achieved the best results with once-weekly injection intervals, which is commonly accepted [15]. Some studies also utilized injection intervals once every 2 weeks and found it to be safe and effective as well. Kontochristopoulus et al. demonstrated different results than in the study conducted by Uppal et al. likely because the keloids were more exposed to treatment permitting better responses. The unique method of 5-FU tattooing reportedly had limited side effects. Sadeghinia and Sadeghinia attributed their low side effect profile to the extended intervals between intralesional treatments (every 4 weeks instead of every 1-2 weeks) [35]. Likewise, the injection technique is plausible source of adverse effects. Nanda and Reddy encountered a much higher proportion of patients with ulceration following treatment and cited this for injection of 5-FU directly into the keloid. They suggested intralesional injections underneath the keloid; however, Fitzpatrick refuted their speculation and encouraged direct injection of 5-FU/TAC into the keloid [18].

With respect to the rates of reoccurrence, Wilson et al. demonstrated the lowest reoccurrence of all studies at $3.75 \%$, which may have been the result of previous excision plus the addition of 5-FU in addition to botulism toxin. This was in contrast to Kontochristopoulus et al. who reported the highest reoccurrence of all the studied included of $47 \%$; this may be attributed to the longer follow-up periods used in this study.
Many studies utilized very short follow-up periods ( $<1$ year), which is too short to draw conclusions on recurrence. For this reason, the majority of studies report a very low reoccurrence rate, and five studies report no reoccurrence. Additionally, the existence of an unintended inclusion bias cannot be excluded, as study protocols may favor patients who produce positive results.

\section{Strengths and Limitations}

This review is one of the first to provide a comprehensive, head-to-head comparison of 5-FU monotherapy and its combination with adjuvant therapies including corticosteroids and lasers for the treatment of HTSs and keloids. The main benefit of this study is its ability to provide the most relevant, evidenced-based clinical data to clinicians posed with the everyday challenge of problematic scars and dissatisfied patients. Direct comparison of various studies is significantly limited by the poor level of evidence available on 5-FU in the context of scar therapy. Additionally, there was substantial heterogeneity among study designs including, but not limited to, the duration of scars, previous treatment failures, treatment intervals, and the number of sessions and injections. HTSs and keloids are similar but distinct pathological entities. Most studies grouped these lesions together and provided no consistent definition. Even more, outcome evaluations were largely varied, with different studies making use of non-standardized subjective and objective measurements, which, under those circumstances, complicate any direct comparisons. Any possible outcome bias, let alone general underlying factors such as the scar location, skin types, sex, race, genetic factors, immune response, and tension across 
suture lines, as well as individual fibroblast activity, is concerning and difficult to assess.

\section{CONCLUSION}

Further studies are needed to better elucidate the fundamental pathophysiology of HTSs and keloids. Greater understanding of these complex mechanisms will permit the development of more specific treatments to target specific pathways. As a whole, 5-FU is an effective remedy for HTSs and keloids if appropriately administered. Information from the data currently published suggests that 5-FU is a useful agent for treatment in monotherapy, but more so in combination with other agents, particularly low-dose corticosteroids [5]. Physicians should consider the utility of 5-FU therapy as an alternative treatment strategy in patients who have failed conventional treatments and are experiencing, or would like to avoid, the undesirable long-term adverse effects of corticosteroid use [5].

\section{ACKNOWLEDGMENTS}

No funding or sponsorship was received for this study or publication of this article. All named authors meet the International Committee of Medical Journal Editors (ICMJE) criteria for authorship for this manuscript, take responsibility for the integrity of the work as a whole, and have given final approval for the version to be published.

Disclosures. Vidhi V. Shah, Adam S. Aldahan, Stephanie Mlacker, Sahal Samarkandy, Mohammed Alsaidan, and Keyvan Nouri have nothing to disclose.
Compliance with Ethics Guidelines. This article is based on previously conducted studies and does not involve any new studies on human or animal subjects performed by any of the authors.

Open Access. This article is distributed under the terms of the Creative Commons AttributionNonCommercial 4.0 International License (http://creativecommons.org/licenses/by-nc/4. $0 /$ ), which permits any noncommercial use, distribution, and reproduction in any medium, provided you give appropriate credit to the original author(s) and the source, provide a link to the Creative Commons license, and indicate if changes were made.

\section{REFERENCES}

1. Davidson $\mathrm{S}$, et al. A primary care perspective on keloids. Medscape J Med. 2009;11(1):18.

2. Bijlard E, Steltenpool S, Niessen FB. Intralesional 5-fluorouracil in keloid treatment: a systematic review. Acta Derm Venereol. 2015;95(7):778-82.

3. Wang XQ, et al. A review of the effectiveness of antimitotic drug injections for hypertrophic scars and keloids. Ann Plast Surg. 2009;63(6):688-92.

4. Berman B, et al. Prevention and management of hypertrophic scars and keloids after burns in children. J Craniofac Surg. 2008;19(4):989-1006.

5. Reish RG, Eriksson E. Scar treatments: preclinical and clinical studies. J Am Coll Surg. 2008;206(4):719-30.

6. Arno AI, et al. Up-to-date approach to manage keloids and hypertrophic scars: a useful guide. Burns. 2014;40(7):1255-66.

7. Bouzari N, Davis SC, Nouri K. Laser treatment of keloids and hypertrophic scars. Int J Dermatol. 2007;46(1):80-8.

8. Ledon JA, et al. Intralesional treatment for keloids and hypertrophic scars: a review. Dermatol Surg. 2013;39(12):1745-57. 
9. Froelich $\mathrm{K}$, et al. Therapy of auricular keloids: review of different treatment modalities and proposal for a therapeutic algorithm. Eur Arch Otorhinolaryngol. 2007;264(12):1497-508.

10. Son IP, et al. Pilot study of the efficacy of $578 \mathrm{~nm}$ copper bromide laser combined with intralesional corticosteroid injection for treatment of keloids and hypertrophic scars. Ann Dermatol. 2014;26(2): 156-61.

11. Cannarozzo G, et al. Flash-lamp pulsed-dye laser treatment of keloids: results of an observational study. Photomed Laser Surg. 2015;33(5):274-7.

12. Azzam OA, et al. Treatment of hypertrophic scars and keloids by fractional carbon dioxide laser: a clinical, histological, and immunohistochemical study. Lasers Med Sci. 2015;31(1):9-18.

13. Polat M, Kaya H, Sahin A. A new approach in the treatment of keloids: UVA-1 laser. Photomed Laser Surg. 2016;34(3):130-3.

14. Jones CD, et al. The use of chemotherapeutics for the treatment of keloid scars. Dermatol Rep. 2015;7(2):5880.

15. Fitzpatrick RE. Treatment of inflamed hypertrophic scars using intralesional 5-FU. Dermatol Surg. 1999;25(3):224-32.

16. Wu XL, Liu W, Cao YL. Clinical study on keloid treatment with intralesional injection of low concentration 5-fluorouracil. Zhonghua Zheng Xing Wai Ke Za Zhi. 2006;22(1):44-6.

17. Gupta S, Kalra A. Efficacy and safety of intralesional 5-fluorouracil in the treatment of keloids. Dermatology. 2002;204(2):130-2.

18. Nanda S, Reddy BS. Intralesional 5-fluorouracil as a treatment modality of keloids. Dermatol Surg. 2004;30(1):54-6 (discussion 56-7).

19. Kontochristopoulos G, et al. Intralesional 5-fluorouracil in the treatment of keloids: an open clinical and histopathologic study. J Am Acad Dermatol. 2005;52(3 Pt 1):474-9.

20. Goldan $\mathrm{O}$, et al. Treatment of postdermabrasion facial hypertrophic and keloid scars with intralesional 5-Fluorouracil injections. Aesthetic Plast Surg. 2008;32(2):389-92.

21. Haurani MJ, et al. 5-Fluorouracil treatment of problematic scars. Plast Reconstr Surg. 2009;123(1):139-48 (discussion 149-51).

22. Saha AK, Mukhopadhyay M. A comparative clinical study on role of 5-flurouracil versus triamcinolone in the treatment of keloids. Indian J Surg. 2012;74(4):326-9.

23. Khare N, Patil SB. A novel approach for management of ear keloids: results of excision combined with 5-fluorouracil injection. J Plast Reconstr Aesthet Surg. 2012;65(11):e315-7.

24. Prabhu A, et al. A randomized controlled trial comparing the efficacy of intralesional 5 -fluorouracil versus triamcinolone acetonide in the treatment of keloids. J Sci Soc. 2012;39(1):19.

25. Manuskiatti W, Fitzpatrick RE. Treatment response of keloidal and hypertrophic sternotomy scars: comparison among intralesional corticosteroid, 5-fluorouracil, and 585-nm flashlamp-pumped pulsed-dye laser treatments. Arch Dermatol. 2002;138(9):1149-55.

26. Apikian M, Goodman G. Intralesional 5 -fluorouracil in the treatment of keloid scars. Australas J Dermatol. 2004;45(2):140-3.

27. Davison SP, et al. Efficacy of intralesional 5-fluorouracil and triamcinolone in the treatment of keloids. Aesthet Surg J. 2009;29(1):40-6.

28. Khan MA, Bashir MM, Khan FA. Intralesional triamcinolone alone and in combination with 5-fluorouracil for the treatment of keloid and hypertrophic scars. J Pak Med Assoc. 2014;64(9): 1003-7.

29. Mutalik S, Patwardhan N. Use of injection five fluorouracil (FFU) with or without injection trimacinolone in the management of hypertrophic scars and keloids. J Cutan Aesthet Surg. 2008;1(1):36.

30. Asilian A, Darougheh A, Shariati F. New combination of triamcinolone, 5-fluorouracil, and pulsed-dye laser for treatment of keloid and hypertrophic scars. Dermatol Surg. 2006;32(7): 907-15.

31. Darougheh A, Asilian A, Shariati F. Intralesional triamcinolone alone or in combination with 5-fluorouracil for the treatment of keloid and hypertrophic scars. Clin Exp Dermatol. 2009;34(2): 219-23.

32. Katz TM, et al. 595-nm long pulsed dye laser and 1450-nm diode laser in combination with intralesional triamcinolone/5-fluorouracil for hypertrophic scarring following a phenol peel. J Am Acad Dermatol. 2010;62(6):1045-9.

33. Hatamipour E, et al. Effects of combined intralesional 5-fluorouracil and topical silicone in prevention of keloids: a double blind randomized 
clinical trial study. Acta Med Iran. 2011;49(3): 127-30.

34. Uppal RS, et al. The effects of a single dose of 5-fluorouracil on keloid scars: a clinical trial of timed wound irrigation after extralesional excision. Plast Reconstr Surg. 2001;108(5):1218-24.

35. Sadeghinia A, Sadeghinia S. Comparison of the efficacy of intralesional triamcinolone acetonide and 5-fluorouracil tattooing for the treatment of keloids. Dermatol Surg. 2012;38(1):104-9.

36. Wilson AM. Eradication of keloids: surgical excision followed by a single injection of intralesional 5-fluorouracil and botulinum toxin. Can J Plast Surg. 2013;21(2):87-91.
37. Blumenkranz MS, Claflin A, Hajek AS. Selection of therapeutic agents for intraocular proliferative disease. Arch Ophthalmol. 1984;102(4):598-604.

38. Alster TS, Williams CM. Treatment of keloid sternotomy scars with $585 \mathrm{~nm}$ flashlamp-pumped pulsed-dye laser. Lancet. 1995;345(8959):1198-200.

39. Gold $\mathrm{MH}$, et al. Updated international clinical recommendations on scar management: part 2algorithms for scar prevention and treatment. Dermatol Surg. 2014;40(8):825-31. 